\title{
Electrodeposition of Magnetic SmCo Films from Deep Eutectic Solvents and Choline Chloride-Ethylene Glycol Mixtures
}

\author{
Gabriele Panzeri, ${ }^{a}$ Matteo Tresoldi, ${ }^{a}$ Christian Rinaldi, ${ }^{b}$ and Luca Magagnin $\circledast^{a, *, z}$ \\ ${ }^{a}$ Dipartimento di Chimica, Materiali e Ingegneria Chimica Giulio Natta, Politecnico di Milano, 20131 Milan, Italy \\ ${ }^{b}$ Dipartimento di Fisica, Politecnico di Milano, 20133 Milan, Italy
}

\begin{abstract}
Suitability of mixtures based on ethylene glycol and choline chloride is evaluated for the electrodeposition of magnetic SmCo alloys. Deep eutectic solvents (DES) are characterized by a wide electrochemical window, allowing the electrodeposition of metallic elements having a highly negative reduction potential. Electrodeposition of unconventional metals with reduction potential well below hydrogen evolution one is, in principle, feasible (e.g. Sm). Moreover, the limited presence of water during the growth of SmCo alloys may reduce oxidation and consequently improve the magnetic properties with respect to the employment of an aqueous bath. Deposits composition is strongly affected by process parameters and bath composition. Increasing choline chloride concentration and/or adding glycine to the solution allows to achieve higher Sm content in the deposit. Potentiostatic electrodeposition has been carried out in a conventional three electrodes cell, with potential interval selected from $-0.7 \mathrm{~V}$ vs $\mathrm{Ag}$ wire to $-0.95 \mathrm{~V}$ vs $\mathrm{Ag}$ wire, keeping the bath under stirring at $70^{\circ} \mathrm{C}$. Magnetic SmCo films with composition from 0 to $50 \mathrm{wt} \% \mathrm{Sm}$ have been obtained with coercivity up to 270 Oe.

(C) The Author(s) 2017. Published by ECS. This is an open access article distributed under the terms of the Creative Commons Attribution 4.0 License (CC BY, http://creativecommons.org/licenses/by/4.0/), which permits unrestricted reuse of the work in any medium, provided the original work is properly cited. [DOI: 10.1149/2.0111714jes] All rights reserved.

(cc) BY
\end{abstract}

Manuscript submitted August 14, 2017; revised manuscript received October 25, 2017. Published November 9, 2017. This was Paper

1562 presented at the Honolulu, Hawaii, Meeting of the Society, October 2-7, 2016.

The role of non-aqueous electrolytes is gaining importance due to their ability to overcome limitations normally observed in the electrodeposition processes from aqueous media. In particular, this is true for the metal elements having reduction potential well below hydrogen evolution one. Ionic liquids are in fact characterized by wider electrochemical windows limiting the onset of secondary processes suppressing the metal reduction one. ${ }^{1-3}$ One practical example is the electrodeposition of rare earth metals and their alloys (e.g. SmCo). Gomez et al. and Cojocaru et al. proposed a study on the electrodeposition of SmCo from a deep eutectic solvent (DES) based on choline chloride and urea $(1 \mathrm{ChCl}: 2 \mathrm{U}) .^{4-6}$ The suitability of such a system for the electrodeposition of both single metals ( $\mathrm{Sm}$ and $\mathrm{Co}$ ) and alloy $(\mathrm{SmCo})$ was verified. Deposits were characterized by a high $\mathrm{Sm}$ content, i.e. 46-79 wt\% Sm, while the optimal composition for the best magnetic performances is $23-25 \mathrm{wt} \% \mathrm{Sm}$, corresponding to the $\mathrm{Sm}_{2} \mathrm{Co}_{17}$ phase. ${ }^{7-9}$ In literature, works on this alloy from both waterbased $^{10-16}$ and non-aqueous solution are reported. ${ }^{17}$ In the former case, fundamental is the employment of glycine as complexing agent as shown by Wei et al. ${ }^{13-15}$ However, in-plane coercivities in the order of $H_{\mathrm{c} \|}=100$ Oe were observed with the formation of $\mathrm{SmO}, \mathrm{Sm}(\mathrm{OH})_{3}$ and $\mathrm{Co}(\mathrm{OH})_{2} .{ }^{14}$ These values are referred to films produced by electrodeposition, an interesting technique from the fabrication point of view but with a huge limitations in terms of compositional and purity control with respect to traditional methods as casting or sputtering through which hard SmCo magnets are obtained $\left(H_{\mathrm{c} \|} \sim \mathrm{kOe}\right)$.

This work consists in the study of different mixtures based on ethylene glycol and choline chloride (1ChCl:2EG and $1 \mathrm{ChCl}: 4.5 \mathrm{EG})$ in order to evaluate the effect of $\mathrm{ChCl}$ concentration on SmCo codeposition and its magnetic properties. Studies on the physical properties of solutions with different $\mathrm{ChCl}$ :HBD (Hydrogen Bond Donor) molar ratio are reported in literature. It has been shown that reducing the amount of choline chloride from $33 \%$ (1ChCl:2EG) to $15 \%$ (1ChCl:6EG) molar, viscosity is reduced from $36 \mathrm{cP}$ to $15 \mathrm{cP}$ at $20^{\circ} \mathrm{C}$ with a slight increase in the conductivity, from $7.61 \mathrm{mS} \mathrm{cm}^{-1}$ to 8.14 $\mathrm{mS} \mathrm{cm}{ }^{-1}$. ${ }^{18,19}$ Thus, by changing the choline chloride concentration in the interval considered, the physical properties of the system are maintained, considering EG as HBD. The different concentration of hydrogen bond acceptor (HBA) allows to have an additional control on alloy film composition. Moreover, the employment of a lower quantity of choline chloride, highly hygroscopic, reduces water contamination

\footnotetext{
*Electrochemical Society Member.
}

${ }^{\mathrm{z}}$ E-mail: luca.magagnin@polimi.it of the solution. Eventually, glycine is added to evaluate its effect in a system different from an aqueous one.

\section{Experimental}

Electrochemical characterization of the bath and deposition experiments have been carried out using AMEL2553 potentiostat/ galvanostat with VApeak software. Experimental apparatus was a conventional three electrodes electrochemical cell, whereas for the preliminary study on the deposit composition dependence on bath agitation, a rotating electrode was employed. For cyclic voltammetry $\mathrm{CV}$, a platinum wire was employed as both anode and cathode. Deposition of magnetic films were performed on copper substrate using a conductive mixed metal oxide mesh $\left(\mathrm{TiO}_{2} / \mathrm{RuO}_{2} / \mathrm{IrO}_{2}\right)$ as counter electrode. Silver pseudo-reference electrode was employed for all the experiments, potential values were referred to Ag wire. Prior each experiment, all electrodes were cleaned with a $10 \mathrm{wt} \% \mathrm{HNO}_{3}$ aqueous solution. Copper substrates have been degreased and subsequently etched in $15 \mathrm{wt} \% \mathrm{H}_{2} \mathrm{SO}_{4}, 3 \mathrm{wt} \% \mathrm{H}_{2} \mathrm{O}_{2}$ aqueous solution. Two different solvents were considered, respectively $1 \mathrm{ChCl}: 4.5 \mathrm{EG}$ and $1 \mathrm{ChCl}: 2 \mathrm{EG}$ molar ratio. Solutions were prepared under constant stirring at $70^{\circ} \mathrm{C}$, $0.04 \mathrm{M}$ cobalt(II) chloride hexahydrate $\left[\mathrm{CoCl}_{2} \cdot 6 \mathrm{H}_{2} \mathrm{O}\right]$ and $0.04 \mathrm{M}$ samarium(III) chloride hexahydrate $\left[\mathrm{SmCl}_{3} \cdot 6 \mathrm{H}_{2} \mathrm{O}\right]$ were added subsequently. Glycine $\left[\mathrm{C}_{2} \mathrm{H}_{5} \mathrm{NO}_{2}\right](0.12 \mathrm{M})$ was added to evaluate its effect on deposition process and film properties. All reagents employed were of analytical grade. Cyclic voltammetries were carried out at $10 \mathrm{mV} \mathrm{s}^{-1}$ and different deposition potentials were considered for the potentiostatic deposition in the range from $-0.7 \mathrm{~V}$ vs $\mathrm{Ag}$ wire to $-0.95 \mathrm{~V}$ vs Ag wire. For all experiments, working temperature was kept at $70^{\circ} \mathrm{C}$. Composition was measured by X-Ray Fluorescence (XRF) with a Fischerscope X-ray XAN. Film surface morphology and crystal structure have been investigated by means of Scanning Electron Microscopy (SEM) and X-Ray Diffraction (XRD) analysis (Philips model PW1830. Cu-Ka1 = 1.54058 ̊). Magnetic properties have been evaluated using a Vibrating Sample Magnetometer (VSM, model EZ9 by MicroSense LLC, Massachusetts, USA).

\section{Results and Discussion}

Cyclic voltammetry was performed in solutions containing individual metal salts; system suitability was thus evaluated for the electrodeposition of Sm and Co films. 1ChCl:2EG DES with no metal salts have been taken as reference to evaluate the onset of reduction peaks in the pure metal solution. For blank solutions, a typical CV curve of 


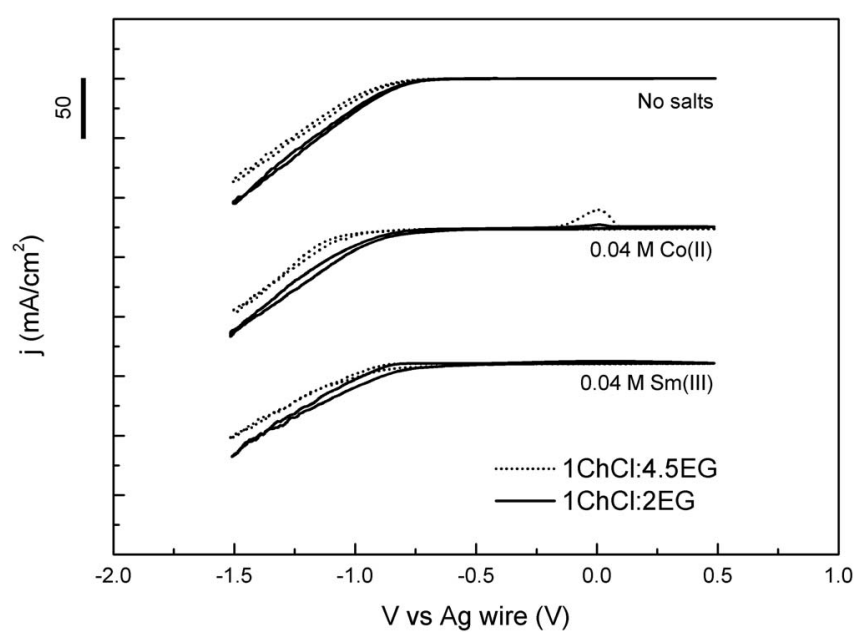

Figure 1. Cyclic voltammetries of $1 \mathrm{ChCl}: 4.5 \mathrm{EG}$ and $1 \mathrm{ChCl}: 2 \mathrm{EG}$ solutions $\left(10 \mathrm{mV} \mathrm{s}^{-1}, 70^{\circ} \mathrm{C}\right.$, stirring).

ChCl:EG system reported in Figure 1 was observed: the lower potential limit is set to $-1.5 \mathrm{~V}$ vs Ag wire because of the significant noise in the signal for more negative potential, related to hydrogen evolution. Results match with the data reported by Badea et al., ${ }^{20}$ where a lower amount of $\mathrm{ChCl}$ in solution corresponds to a wider electrochemical window. Adding single metal salts, there were no significant variations in the CV. For $0.04 \mathrm{M}$ cobalt(II) solution, no reduction peak was observed. On the other hand, there was a significant anodic peak assessed to Co film stripping for the $1 \mathrm{ChCl}$ :4.5EG solution. while it was less intense for $1 \mathrm{ChCl}$ :2EG one. Considering the addition of $0.04 \mathrm{M}$ samarium(III), no reduction peaks and corresponding anodic peaks were observed for both the solutions. Same results were observed for higher salt concentrations, e.g. 0.08 M samarium(III). Thus, such a system seems to be not suitable for the deposition of metallic samarium film on $\mathrm{Pt}$ in the considered potential range. More negative cathodic limits were selected but differences in the electrochemical behavior were not observed.

SmCo codeposition was firstly studied from a solution containing $0.04 \mathrm{M} \mathrm{SmCl}_{3} \cdot 6 \mathrm{H}_{2} \mathrm{O}$ and $0.04 \mathrm{M} \mathrm{CoCl}_{2} \cdot 6 \mathrm{H}_{2} \mathrm{O}$. Voltammetry curve showed a wide reduction peak at $-0.9 \mathrm{~V}$ vs $\mathrm{Ag}$ wire for the $1 \mathrm{ChCl}: 4.5 \mathrm{EG}$ solution. Even though it is not possible to identify two different reduction peaks, respectively corresponding to samarium and cobalt (Figure 2), the presence of both Sm and Co ions helps the codeposition of SmCo through an induced codeposition mechanism, as observed for SmCo alloys from molten salts. ${ }^{21}$ As previously shown, the $1 \mathrm{ChCl}$ :2EG curve is shifted toward positive potential values showing a reduction peak with lower intensity at $-0.6 \mathrm{~V}$ vs $\mathrm{Ag}$ wire. In both cases, during the forward scan (from 0 to $-1.5 \mathrm{~V}$ vs Ag wire), a film was formed on $\mathrm{Cu}$ substrate and subsequently removed rising the potential toward $+0.5 \mathrm{~V}$ vs $\mathrm{Ag}$ wire.

Subsequently, $0.12 \mathrm{M}$ glycine has been added to both solutions. Different studies on aqueous solutions report the $3[\mathrm{Gly}]:[\mathrm{Co}]^{2+}$ ratio as the most suitable for codeposition of Co and Sm; a higher concentration of glycine would in fact hinder the Sm deposition. ${ }^{13-15}$ The same concentration ratio has been selected also for our systems despite based on different chemistry. From the CV curve (Figure 3), it is evident the effect of glycine on the electrochemical behavior of the bath, especially for the $1 \mathrm{ChCl}: 4.5 \mathrm{EG}$ solution. Voltammetry curve presents two reduction peaks at $-0.85 \mathrm{~V}$ vs $\mathrm{Ag}$ wire and $-1 \mathrm{~V}$ vs $\mathrm{Ag}$ wire, attributed to Co and Sm reduction respectively. Moreover, curves shift toward positive potential, favoring the Sm codeposition in the deposit. In the $1 \mathrm{ChCl}$ :2EG curve, a first reduction peak is found at $-0.75 \mathrm{~V}$ vs $\mathrm{Ag}$ wire and a smaller, less intense, at $-0.92 \mathrm{~V}$ vs Ag wire. With respect to glycine-free solution, reduction process is favored and a more intense anodic peak is observed.

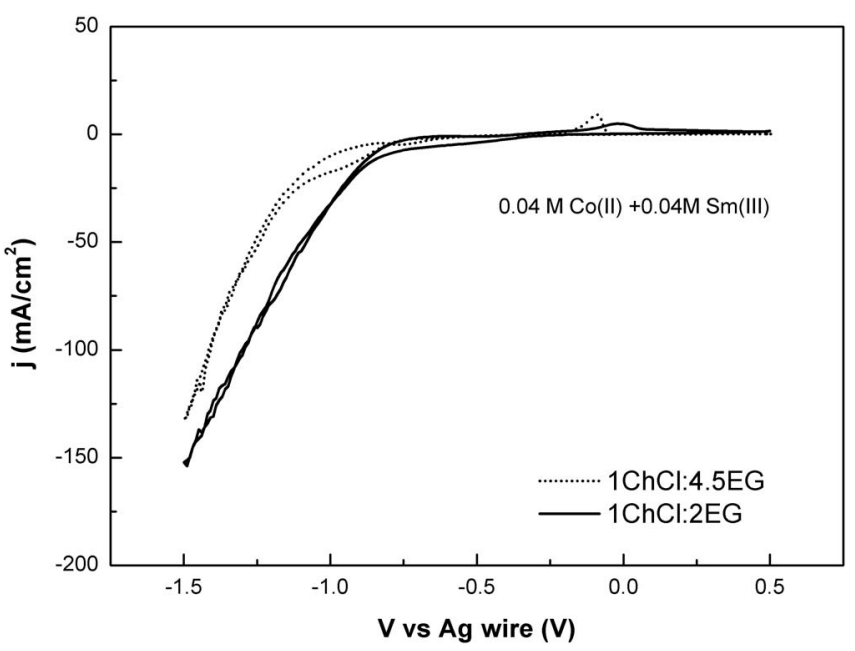

Figure 2. Cyclic voltammetries of $0.04 \mathrm{M} \quad \mathrm{CoCl}_{2} \cdot 6 \mathrm{H}_{2} \mathrm{O}, \quad 0.04 \mathrm{M}$ $\mathrm{SmCl}_{3} \cdot 6 \mathrm{H}_{2} \mathrm{O}$ solutions for different choline chloride concentration. (10 $\mathrm{mVs}^{-1}, 70^{\circ} \mathrm{C}$, stirring).

Glycine effect on deposit composition was evaluated by means of potentiostatic deposition in the potential window from $-0.7 \mathrm{~V}$ vs $\mathrm{Ag}$ wire to $-0.95 \mathrm{~V}$ vs Ag wire. Plating process was carried out under stirring, stagnant conditions were found not suitable for SmCo electrodeposition. Similar results were observed for relatively high negative potential with formation of a black oxide powder at -0.9 $\mathrm{V}$ vs Ag wire. Consequently, deposits were inhomogeneous in composition and thickness; this may be probably due to the relatively high viscosity of $\mathrm{ChCl}$ :EG system. On the other hand, because of the hygroscopic nature of choline chloride, a certain amount of water is always present in solution and hydrogen evolution at the cathodic surface can occur during the electrodeposition process affecting surface morphology. For all these reasons, stirring plays a fundamental role as shown from the preliminary study on $1 \mathrm{ChCl}$ :4.5EG solution where increasing stirring (rotating disk electrode: from 10 to $200 \mathrm{RPM}$ ) decreases the Sm concentration in the deposits. ${ }^{22}$ After having defined the solution agitation effect, potentiostatic depositions were carried out in a conventional three-electrode electrochemical cell where the magnetic stirrer was set to constant value (300 RPM), different deposition potentials were selected from $-0.7 \mathrm{~V}$ vs Ag wire to $-0.95 \mathrm{~V}$ vs $\mathrm{Ag}$ wire. Four different solutions were considered to study the role of

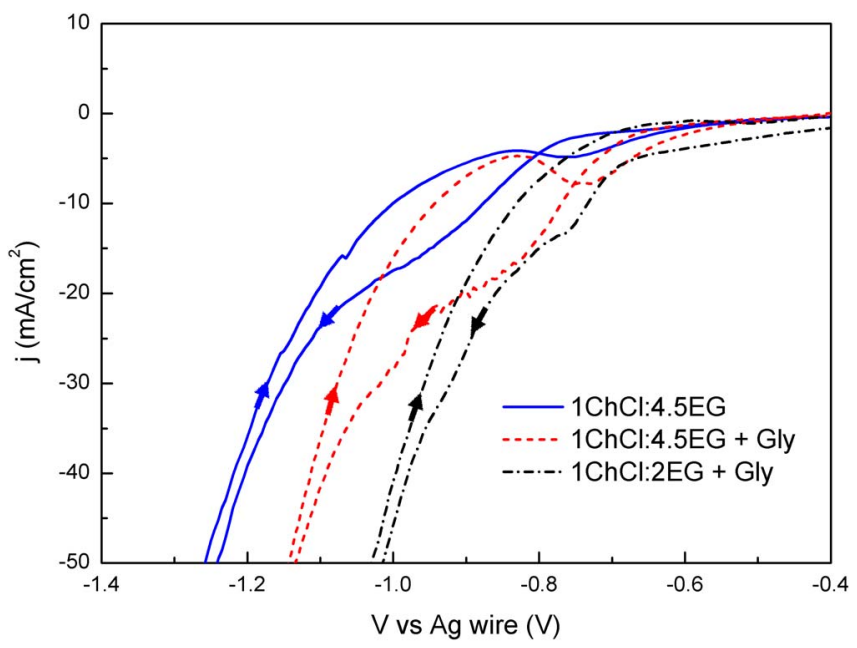

Figure 3. Cyclic voltammetries of $0.04 \mathrm{M} \mathrm{CoCl} 2 \cdot 6 \mathrm{H}_{2} \mathrm{O}, 0.04 \mathrm{M}$ $\mathrm{SmCl}_{3} \cdot 6 \mathrm{H}_{2} \mathrm{O}$ solutions for different choline chloride concentration and with the addition of $0.12 \mathrm{M}$ glycine. $\left(10 \mathrm{mVs}^{-1}, 70^{\circ} \mathrm{C}\right.$, stirring). 
Table I. Range of film composition in the potential interval $-0.7 \mathrm{~V}$ vs Ag wire to $-0.95 \mathrm{~V}$ vs $\mathrm{Ag}$ wire, at $70^{\circ} \mathrm{C}$ and stirred conditions: $0.04 \mathrm{M} \mathrm{CoCl}_{2} \cdot 6 \mathrm{H}_{2} \mathrm{O}, 0.04 \mathrm{M} \mathrm{SmCl}_{3} \cdot 6 \mathrm{H}_{2} \mathrm{O}, 0.12 \mathrm{M}$ glycine.

\begin{tabular}{cc} 
Solution & $\mathrm{wt} \% \mathrm{Sm}$ \\
\hline $1 \mathrm{ChCl}: 4.5 \mathrm{EG}$ & $0.5-2$ \\
$1 \mathrm{ChCl}: 4.5 \mathrm{EG}$ (Gly) & $5-29$ \\
$1 \mathrm{ChCl}: 2 \mathrm{EG}$ & $7-25$ \\
$1 \mathrm{ChCl}: 2 \mathrm{EG}$ (Gly) & $18-44$
\end{tabular}

choline chloride concentration and the presence of glycine in the bath. Sm concentration and deposition potential match with the voltammetry curve: increasing the driving force of the plating process leads to higher samarium content in the deposit. Film composition was also highly dependent on the selected system (Table I). The majority of the deposits showed a metallic aspect although the film color was blackish for high Sm content; this may be an indication of oxygen presence in the film. On the other hand, by increasing further the deposition potential ( $-0.9 /-0.95 \mathrm{~V}$ vs Ag wire), the formation of oxide/hydroxide powders on the cathodic surface was observed. Finally, for three of the four solutions it was possible to obtained the target composition of 20-25 wt\% Sm. In this view, ethylene glycol represents a better alternative to urea considering choline chloride as metal halide for Corich SmCo alloys. Gomez et al. and Cojocaru et al. showed a study on $1 \mathrm{ChCl}: 2 \mathrm{U}$ solution where the minimum samarium concentration obtained was $45 \mathrm{wt} \% \mathrm{Sm}$, whereas $\mathrm{Sm}_{2} \mathrm{Co}_{17}$ is around $23 \mathrm{wt} \% \mathrm{Sm} .{ }^{4,5}$ Moreover, the employment of ethylene glycol instead of urea lowers significantly the viscosity thus increasing the conductivity.

Both choline chloride concentration and glycine affect significantly film composition. As observed from the cyclic voltammetries, where the curve is shifted toward more positive values, higher samarium content can be obtained for a given deposition potential. The higher $\mathrm{ChCl}$ concentration seems to bring to a different complexation between $\mathrm{Sm}$ and $\mathrm{Co}$ ions. For $1 \mathrm{ChCl}: 4.5 \mathrm{EG}$, its concentration is in fact limited to a maximum of $2 \mathrm{wt} \% \mathrm{Sm}$; for potential values lower than $-0.9 \mathrm{~V}$ vs Ag wire, oxide powder was formed. On the other hand, it was possible to reach $50 \mathrm{wt} \% \mathrm{Sm}$ increasing $\mathrm{ChCl}$ to $33 \%$ molar (1ChCl:2EG): this solvent composition corresponds to the eutectic point and it is comparable with the $1 \mathrm{ChCl}: 2 \mathrm{U}$ solution. The amount of glycine added was three times the cobalt concentration; such a ratio was reported as effective for the codeposition of SmCo in aqueous system. Wei et al. ${ }^{13-15}$ demonstrated how a higher glycine quantity leads to a lower Sm content in the deposit; the same [Gly]/[Co $]^{2+}$ has been adapted to our system. Results in potentiostatic conditions are in agreement with cyclic voltammetry where a more evident reduction process was observed. At a given deposition potential, Sm content is significantly increased; this is particularly true for the $1 \mathrm{ChCl}$ :4.5EG solution. Moreover, film growth is favored, thicknesses in the order of micrometers can be easily achieved while for the glycine-free solution the maximum thickness obtained is around $1 \mu \mathrm{m}$, especially for relatively high $\mathrm{Sm}$ content film $(\mathrm{Sm}>15 \mathrm{wt} \%)$. The presence of glycine thus affects the growth kinetic; changes in the morphology are consequently expected. SEM images of deposits having 20 wt\% Sm, obtained from two different solutions, are shown. Glycine addition resulted in a more compact and smooth surface showing bigger cracks but less in number. Without additive, film morphology is granular with a more disordered structure where a higher amount of cracks, smaller in size, are observed (Figure 4). Considering the $\mathrm{XRD}$ spectra in Figure 5, pure Co film, obtained from $1 \mathrm{ChCl}: 2 \mathrm{EG}$ glycine-containing solution, is characterized by a hexagonal structure (HCP) with no preferential orientation. SmCo films obtained from the glycine-solution showed an Co HCP microstructure with low intensity $\mathrm{Co}(100)$ and $\mathrm{Co}(101)$ reflections. On the other hand, without glycine, a single reflection peak is observed corresponding to the $\mathrm{HCP} \mathrm{Co}(002)$ orientation. A Co metal matrix with $\mathrm{Sm}$ atoms is likely to be formed.

Vibrating sample magnetometer (VSM) was employed to magnetically characterize the electrodeposited films. Table II contains a
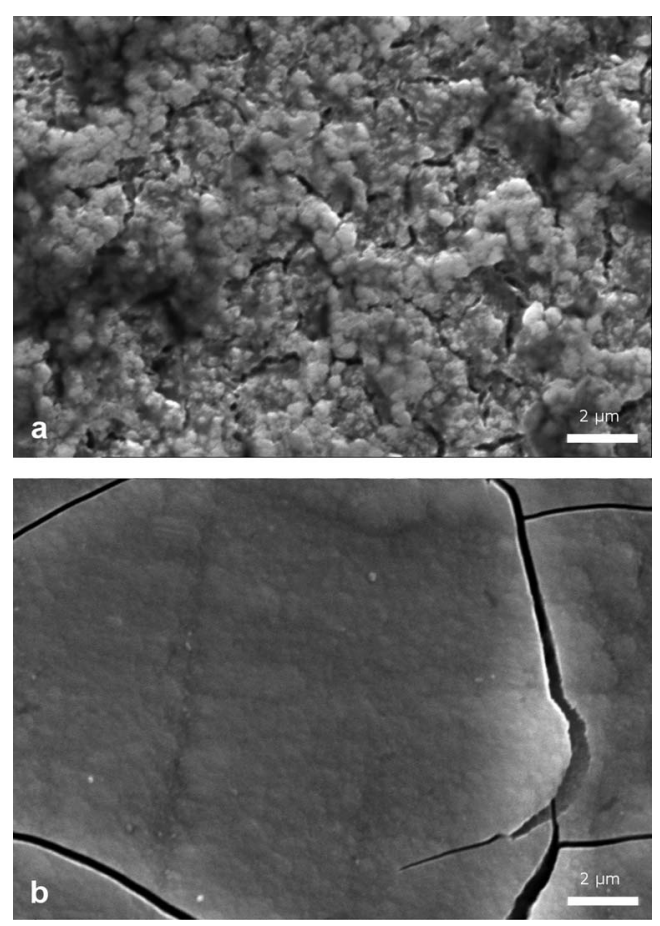

Figure 4. Deposit morphology of SmCo alloys (20 wt $\% \mathrm{Sm})$ obtained from $1 \mathrm{ChCl}$ :2EG solution. a) Glycine-free solution. b) Glycine-containing solution.

summary of samples and their in-plane magnetic properties. Pure Co deposit from glycine bath was measured as reference. As shown in Figure 6a, the film presents a magnetic hard axis in the out-of-plane direction, while the in-plane hysteresis loop shows a coercivity of $73 \mathrm{Oe}$ $(5.8 \mathrm{~A} / \mathrm{m})$. The $\mathrm{S}$-shaped hysteresis loop (relatively low squareness) could be ascribed to the polycrystalline nature of the electrodeposited Co film, as confirmed by the XRD spectrum of Co (Figure 5). In general and no matter the solution used for the growth, the addition of the rare-earth element $\mathrm{Sm}$ improves the in-plane coercivity of the deposits, as shown in Figures 6b-6c for the SmCo samples. As in Co, the out-of-plane direction results to be a hard axis for the magnetization (Figures 6b-6c). The SmCo deposited in the glycine-containing solution shows a coercive field of $100 \mathrm{Oe}(8.0 \mathrm{kA} / \mathrm{m})$, higher than Co film and compatible with those reported in literature for electrodeposition from aqueous baths. ${ }^{13-15}$ On the other hand, SmCo film grown in a $1 \mathrm{ChCl}$ :2EG solution without glycine presents a significantly higher

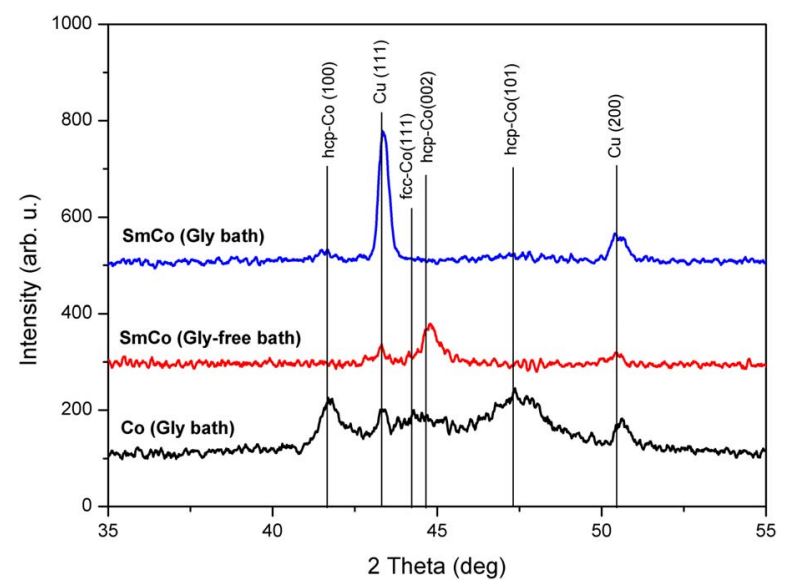

Figure 5. XRD spectra of Co electrodeposit from glycine containing bath, SmCo electrodeposit with $20 \mathrm{wt} \% \mathrm{Sm}$ from glycine free bath and SmCo electrodeposit with $20 \mathrm{wt} \% \mathrm{Sm}$ from glycine-containing bath in $1 \mathrm{ChCl}: 2 \mathrm{EG}$. 
Table II. Magnetic properties obtained by the in-plane hysteresis loops of the electrodeposited films.

\begin{tabular}{|c|c|c|c|c|}
\hline Sample & Solution & $\mathrm{wt} \% \mathrm{Sm}$ & in-plane $\mathrm{H}_{\mathrm{C}}[\mathrm{Oe}]$ & Loop squareness $\mathrm{M}_{\mathrm{r}} / \mathrm{M}_{\text {sat }}$ \\
\hline Co & 1ChCl:2EG (Gly) & 0 & 73 & 0.25 \\
\hline SmCo (gly-free) & 1ChCl:2EG & 20 & 270 & 0.21 \\
\hline SmCo (gly) & 1ChCl:2EG (Gly) & 20 & 100 & 0.27 \\
\hline
\end{tabular}

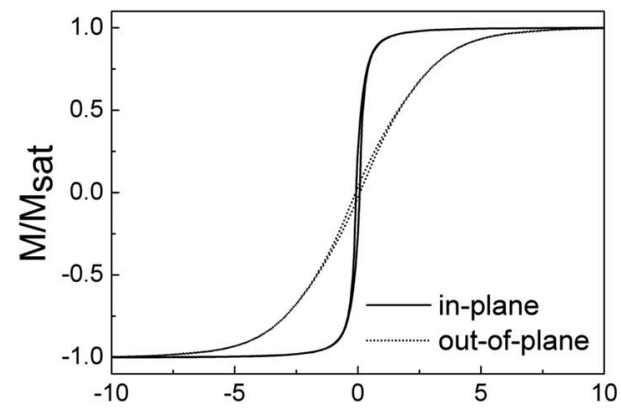

a)
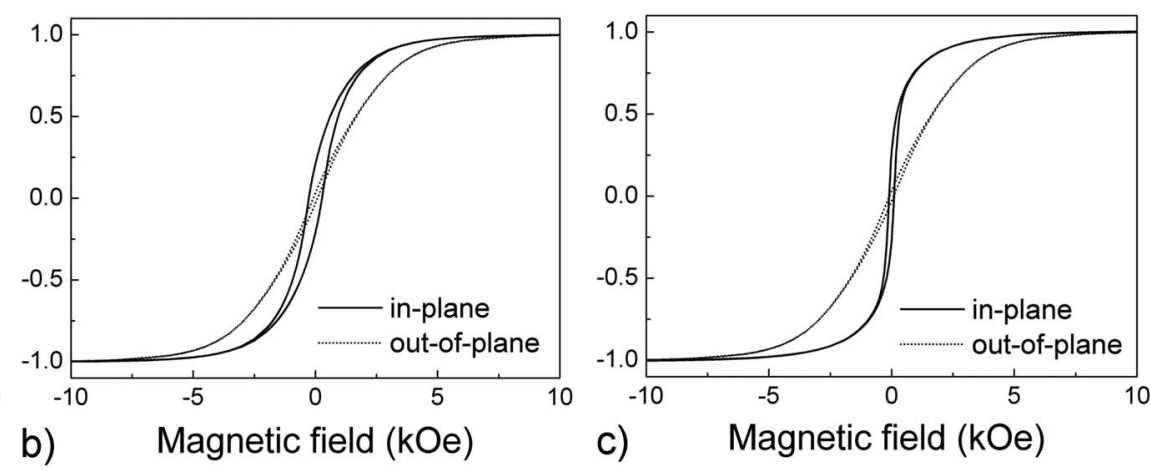

Figure 6. In-plane and out-of-plane hysteresis loops measured by vibrating sample magnetometry on electrodeposited thin film of $\mathrm{Co} / \mathrm{Cu}(\mathrm{a}), \mathrm{SmCo} / \mathrm{Cu}$ grown in $1 \mathrm{ChCl}: 2 \mathrm{EG}(\mathrm{b}), \mathrm{SmCo} / \mathrm{Cu}$ grown in $1 \mathrm{ChCl}$ :2EG with the addition of glycine (c).

coercive field $H_{\mathrm{c}}=270 \mathrm{Oe}(21.5 \mathrm{~A} / \mathrm{m})$, in agreement with the value reported for the $1 \mathrm{ChCl}: 2 \mathrm{U}$ system. ${ }^{4-6}$ The out-of-plane direction is again a hard axis for the magnetization (Figure 6b). A comparison between the in-plane $\mathrm{M}(\mathrm{H})$ curves for the three samples is shown in Figure 7. The different magnetic properties of the SmCo films can be related to the extremely different morphology of the two, as shown in Figures 4a-4b. While the sample with glycine has smoother surface and presents a higher crystalline ordering, the film grown without glycine is granular and disordered. The higher concentration of defects in the latter could be responsible for a significant pinning of the magnetization and thus of the increase of the coercivity. The misalignment of grains could also be the cause for the reduction of the remanent magnetization (the squareness $M_{\mathrm{r}} / M_{\text {sat }}$ is $21 \%$ without glycine and increases to $27 \%$ in the film grown with glycine addition).

\section{Conclusions}

Choline chloride:ethylene glycol based solutions have been proven to be suitable for SmCo codeposition: films with $\mathrm{Sm}$ content corre-

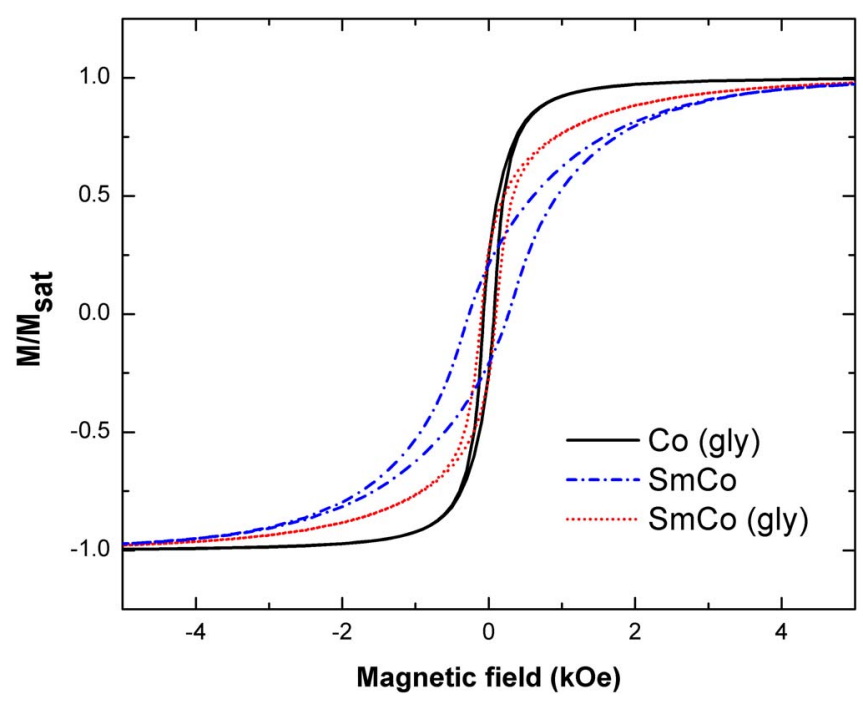

Figure 7. Comparison between the hysteresis loops of the three electrodeposited films. sponding to $\mathrm{Sm}_{2} \mathrm{Co}_{17}$ composition have been obtained. The addition of choline chloride and glycine promotes the SmCo codeposition, with an increase in Sm content in the films. Glycine promotes also film growth by increasing the maximum achievable thickness: the resulting film shows a smooth morphology, even if cracks are present. From the point of view of magnetic properties, SmCo films are ferromagnetic. The addition of the rare-earth element $\mathrm{Sm}$ to Co increases the in-plane coercive field with coercivity values up to $270 \mathrm{Oe}$.

\section{ORCID}

Luca Magagnin (D https://orcid.org/0000-0001-5553-6441

\section{References}

1. A. P. Abbott and K J. McKenzie, Physical Chemistry Chemical Physics, 8, 4265 (2006).

2. T. Welton, Chem Rev., 99, 2071 (1999).

3. R. Bernasconi, G. Panzeri, A. Accogli, F. Liberale, L. Nobili, and L. Magagnin, Electrodeposition from deep eutectic solvents. In: Progress and developments in ionic liquids, InTechOpen, Croatia (2017).

4. E. Gómez, P. Cojocaru, L. Magagnin, and E. Valles, J. Electroanal. Chem., 658, 18 (2011).

5. P. Cojocaru, L. Magagnin, E. Gomez, and E. Valles, Mater. Lett., 65, 3597 (2011).

6. E. Gomez, E. Valles, P. Cojocaru, A. Raygani, and L. Magagnin, ECS Transactions, 41, 3 (2012).

7. H. Okamoto, Journal of Phase Equilibria and Diffusion, 32, 165 (2011).

8. O. Gutfleisch, High-temperature samarium cobalt permanent magnets. In: Nanoscale magnetic materials and applications, Springer, Germany (2009).

9. Y. Q. Guo, W. Li, J. Luo, W. C. Feng, and J. K. Liang, J. Magn. Magn. Mater, 303, e367 (2006).

10. K. Chouarbi, M. Woytasik, E. Lefeuvre, and J. Moulin, DC and pulsed electrodeposition of SmCo thin films. In: Design, Test, Integration and Packaging of MEMS/MOEMS (DTIP), Cannes, France, IEEE (2012).

11. K. Chouarbi, M. Woytazik, E. Dufour-Gergam, E. Lefeuvre, and J. Moulin, ECS Transactions, 45, 15 (2013).

12. X. Long, G. Guo, X. Li, Q. Xia, and J. Zhang, Thin Solid Films, 548, 259 (2013).

13. J. Wei, M. Schwartz, and K. Nobe, ECS Transactions, 1, 273 (2006).

14. J. Wei, M. Schwartz, and K. Nobe, J. Electrochem. Soc., 155, D660 (2008).

15. J. Wei, M. Schwartz, and K. Nobe., ECS Transactions, 16, 129 (2009).

16. J. Zhang, P. Evans, and G. Zangari, J. Magn. Magn. Mater., 283, 89 (2004).

17. A. Ispas, M. Buschbeck, S. Pitula et al., ECS Transactions, 16, 119 (2009).

18. A. P. Abbott, R. C. Harris, and K. S. Ryder, The Journal of Physical Chemistry B, 111, 4910 (2007)

19. O. Ciocirlan, O. Iulian, and O. Croitoru, Rev. Chim., 61, 721 (2010).

20. M. M. Badea, A. Cojocaru, and L. Anicai, UPB Sci. Bull. Series B, 76, 21 (2014).

21. P. Liu, Y. Du, Q. Yang, Y. Tong, and G. A. Hope, J. Electrochem Soc., 153, C57 (2006).

22. G. Panzeri and L. Magagnin, ECS Transactions, 75, 31 (2016) 